Alison J Smith MB BS BSC FRCA, Neville W Goodman MA DPHIL BM BCH FRCA

\title{
The hypertensive response to intubation. Do researchers acknow- ledge previous work?
}

Purpose: To see whether investigators of a circumscribed research topic, the haemodynamic response to orotracheal intubation, review and cite previous work. A 1989 editorial about the response was critical of investigators for measuring physiology but not outcome; for nonetheless making recommendations; for studying only patients not at risk; and for implying patients are at risk when this is not certain

Methods: A systematic Medline search was made for English language reports published during or after 1990. and their citation lists read for missed reports. All retrieved papers were read for citation of the editorial and for acknowledgment of its criticisms. Citations were tabulated, and cross-referenced between papers, to see whether blocks of citations had been obtained from other investigators' reports.

Results: Eighty-one full reports, from 48 groups of investigators, were obtained. The 1989 editorial was cited twice. All studies included physiological measurements, but none reported long-term outcome. There was no comment on the need to know outcome in 39 reports. Pre-existing risk factors were exclusions in 65 studies. In 56 papers, complications of the response were given as the reason for the study; in 41 of these papers only healthy subjects were studied. In total. 249 references about the response were identified from the 81 papers. There was no obvious evidence that citations were obtained from others' papers.

Conclusion: Recognised deficiencies in research method were not acknowledged. When submitting work for publication, investigators should provide evidence of how they searched for previous work.

Objectif : Exarniner si les investigateurs travaillant sur un projet de recherche particulier, i.e., la réaction hémodynamique provoquées par l'intubation orotrachéale, parcouraient les publications antérieures et en faisaient mention. Un éditorial publié en 1989 sur cette réaction critiquait les auteurs d'avoir mesuré la physiologie et non les résultats ; malgré cela, d'avoir fait des recommandations; d'avoir étudié des patients qui rétaient pas à risque : et d'avoir conclu que des patients étaient à risque sans en être sûrs.

Méthodes : Une recherche systématique était effectuée sur Medline des comptes rendus de langue anglaise parus sur ce sujet pendant ou après 1990 avec une vérification de la bibliographie à la recherche de citations omises. Tous les articles recensés étaient fouillés sur leurs références à l'éditorial et la constatatıon des critiques formulées. Les citations étaient compilées et les références confrontées pour voir si les blocs de citations provenaient de comptes rendus publiés par d'autres auteurs.

Résultats : Quatre-vingt-un comptes rendus complets, publiés par 48 groupes d'investigateurs ont été recensés. L'éditorial de 1989 était cité deux fois. Toutes les études faisaient état de mesures physiologiques mais aucune ne rapportait de résultats à long terme. Aucun commentaire sur la nécessité de connaîre les résultats ne figurait dans 39 comptes rendus. Dans 65 études, les facteurs de risques pré-existants étaient omis. Dans 56 articles, les complications causées par la réaction étaient fournies comme motifs de l'étude : dans 41 de ces études, seuls des sujets bien portants étaient étudiés. Au total, 249 références sur la réaction étaient identifiées dans les 81 articles. II n'existait pas d'évidence démontrant que les citations provenaient d'articles publiés par d'autres auteurs.

Conclusion : Les faiblesses incontestables du protocole de recherche niavaient pas été reconnues. Quand ils soumettent des travaux pour publication, les investigateurs devraient montrer de quelle façon ils ont analysé les travaux antérieurs.

From the University Department of Anaesthesia, Medical School Unit, Southmead Hospital, Bristol, BS10 5NB, UK.

Address correspondence to: Dr Goodman.

TEL 0117 9505050: e-mail: Nev.W.Goodman@bris.ac.uk

Accepted for publication September 22, 1996. 
A $\mathrm{N}$ early step in answering a research question is to review what is already known. ${ }^{1} \mathrm{~A}$ common complaint is that researchers do not always review previous work properly and, when they do, choose only to cite references that suit their cause. ${ }^{2}$ Altman gives this and drawing unjustified conclusions as common faults of medical research. ${ }^{3}$

Failure of proper review is a source of publication bias, which Chalmers et al. consider has three stages: prepublication, publication, and postpublication. ${ }^{4}$ Publication bias in this scheme is the tendency for negative findings not to be published; postpublication bias occurs in the later interpretation, review and meta-analysis of published work. Prepublication bias includes inadequate review, which Chalmers et al. put down to the ignorance and sloth of the investigators.

For many research questions, previous knowledge is drawn from different fields. The indexing and availability of articles can cause difficulties. Researchers may genuinely miss important articles and one cannot know whether missed citations are by omission or commission. The modification by drugs of the haemodynamic response to tracheal intubation is a circumscribed topic and so is a good example of a research topic for which quite simple indexed searches should turn up most of the previous work. In 1989 Thomson wrote a critical perspective upon the subject, the only indexed summary of the topic in the previous 10 years. ${ }^{5} \mathrm{He}$ made four points: investigators measure physiological responses but give no information on outcome; they nonetheless make recommendations about the need to modify the response; the patients included in the studies are rarely the patients at risk if the response is left unmodified; and it is by no means certain that patients thought to be at risk actually are at risk. One of us (NG), although having no special interest in the haemodynamic response to intubation, had read the editorial at the time and was impressed by the points made, not only because of Thomson's cogent criticisms of the specific research topic, but because of the wider implications for the organisation of medical research.

As a steady stream of research publications continued to appear, it was apparent that none of them was citing this editorial. When we considered studying this formally, we thought that anyone investigating the effect of drugs on the haemodynamic response to intubation after 1989 should have known about Thomson's editorial. We considered that citation of the editorial, or more importantly an attempt in the study design or report to consider the points made by Thomson, would be evidence of review of previous work. A preliminary search in August 1994 of Medline turned up 39 research papers published since 1990. A citation search turned up five citations of Thomson's editorial, only one in a research paper. Three citations were by NG, in an editorial and two letters. Our suspicions seemed worth following up.

By the time of Thomson's editorial, there were a number of drugs already known to modify the response. We were also interested to know whether newly investigated drugs would be compared with them.

\section{Methods}

In September 1995, we did a logical, structured Medline search (Silver Platter) using the terms haemodynamic, hypotension, cardiovascular, pressor, intubation and laryngoscopy for English language papers published from 1990 onwards. We devised the search strategy on the index terms of papers turned up in the preliminary search. We ignored papers published in 1989, to allow investigators reasonable time to see Thomson's editorial of July 1989. We ignored papers not in English because we would have needed full translation. We concentrated on fully reported studies, ignoring abstracts, of the haemodynamic response to conventional laryngoscopic orotracheal intubation. We attempted to obtain copies of all the papers, excluding letters and abstracts. We checked through the reference lists of these papers for papers not turned up by the Medline search. For each paper we noted whether Thomson was cited, the investigators' stated reasons for doing the study, and whether the investigators had explicitly considered Thomson's critical points.

For studies of pharmacological modifications of the response, we noted whether new drugs were compared with a previously described treatment, placebo or both.

We examined the reference lists for each article, assigning index numbers to the primary papers and index letters to cited papers. We drew up tables to allow visual searches for obvious patterns of copying citation lists between papers by looking for recurring patterns of blocks of citations occurring in papers from different investigators. We applied no formal statistical testing to this.

\section{Results}

\section{The retrieved papers}

The Medline search identified 73 relevant papers, including Thomson's editorial. We identified and obtained a further eight papers from the reference lists of retrieved papers. We failed to obtain copies of two 
of these 81 papers. We found two more papers in recent journals in our medical library. In total, we read 81 papers from 48 groups of investigators, describing the haemodynamic response to orotracheal intubation by conventional laryngoscopy.

Sixteen papers were from the British Journal of Anaesthesia, 15 from the Canadian Journal of Anaesthesia, 12 from Anaesthesia, 11 from Acta Anaesthesiologica Scandinavica, 8 from the Journal of Clinical Anesthesia. Anesthesiology, Anesthesia and Analgesia, and Anaesthesia and Intensive Care between them published seven of the papers. Ten other journals accounted for the remaining 12 papers.

\section{Direct citations of Thomson}

Two papers cited Thomson, one in the introduction and the other in the discussion. Both citations were used to support assertions, the first to the use of many agents to obtund the response, the second to the need to attenuate the responses in patients with cardiovascular disease.

\section{The investigators' reasons and conclusions, related to} Thomson's criticisms

The potential for complications from the response, particularly in patients with cardiovascular disease, was given as a reason for doing the study in 56 papers. In 41 of these studies, only healthy subjects were included. In 22 studies, investigators stated, or implied, that haemodynamic stability was a 'goal' of anaesthesia without explaining why. Three studies were of new methods of measuring the response, for example from finger blood pressure, with no indication of why the response might be interesting or how using the different method would give fresh insights.

There was no comment on outcome in 39 studies. Nonetheless, investigators in 19 of these studies concluded that their technique usefully modified the response, with comments in 14 papers that further studies were needed in patients at risk.

Short-term adverse events, such as electrocardiographic evidence of ischaemia or cardiac arrhythmias during intubation, were described in 35 studies. Clinical recommendations based on their technique were made by investigators in $\mathbf{1 8}$ of these studies.

Investigators made comments about other outcomes in seven studies, for example, fetal outcome in studies of pregnancy-induced hypertension. Long term complications were not reported in any study.

In 65 studies, patients studied were in ASA classes 1 or 2 and pre-existing hypertension or cardiac disease were specific exclusions. For 35 of these studies, investigators acknowledged in the introduction that the response was most likely to be harmful in patients with pre-existing cardiovascular or cerebral disease.

\section{Comparisons made in the studies}

Sixteen of the studies were of modifications of the response by alteration of anaesthetic technique, for example, changing the force required for intubation or using different intravenous induction agents. A new drug to modify the response was compared with placebo in 42 studies. Sixteen of these studies came from the same group of investigators, investigating 15 different drugs. Five of the 42 studies included patients who might be considered at risk.

In ten studies, six including at risk patients, a new drug or altered dose was compared with a previously described drug or dose. In ten studies, three including at risk patients, a new drug was compared with a previously described drug and with placebo.

\section{Patterns of citation}

A total of 249 citations relating to the haemodynamic response to intubation was identified from the reference lists of the 81 articles. There were 18 references cited ten or more times. For seven of these, over two thirds of the citations were by the same group of investigators, whose papers read very similarly and tended to quote the same references. Excluding these left 11 references cited ten or more times.

No clear patterns emerged from our documentation of the citations. In particular, we saw no evidence that citations were being copied from earlier articles coming from different groups. Four of the most frequently cited 11 papers were early reports (made in $1951,1970,1971$ and 1987) of the hypertensive response, either in healthy patients or in those with cardiovascular disease. One citation was to the only reference that we could trace of long term complications undeniably arising from the response, and this report of two cases was quoted in 22 articles. The other frequently cited papers were reports of interventions with various drugs to attenuate the response.

\section{Discussion}

Only two of the 81 papers we examined cited Thomson's editorial, and we question whether these citations were appropriate: the authors cited Thomson to support their research - what Brooks describes as 'positive credit's - but Thomson was being critical of the field of study.

The editorial was Thomson's own view, and subsequent investigators may disagree with it, but that does not mean they can ignore it. Review articles and editorials are often not cited in favour of citation of the 
original research articles, but later investigators must acknowledge if there has been published criticism of a method or field of study. It is not necessary to have researched a field to enable valid criticism. We are dismayed that in over two-thirds of our sample of $\mathbf{8 1}$ papers the investigators failed to consider the critical points made by Thomson. Thomson wrote of investigators making presumptions of benefit, having studied only physiology and not outcome, and investigators continue to presume.

Medline searches do not turn up all the relevant papers. ${ }^{7}$ Chalmers et al. require investigators to look further than on-line searching, ${ }^{4}$ which is what we did, checking for missed papers by looking at the reference lists of retrieved papers. But our Medline search did turn up Thomson's editorial, and we think it unlikely that all 46 sets of investigators, each doing a Medline search, would miss it. Investigators may miss work because journals are not readily available, or because of national bias. Neither of these is a valid reason for ignoring previous work, but 15 of the papers were published in the same journal that published the editorial.

Without asking the investigators directly, we cannot know for certain whether the fault is one of omission (failure to review adequately) or of commission (failing to acknowledge a known critical article). We believe that our evidence points towards commission: that investigators are choosing not to cite critical opinion.

Long term problems resulting from the haemodynamic response to intubation are rare, and have been reported only in patients at risk from pre-existing hypertension, cardiac disease or intracranial abnormalities. ${ }^{8-11}$ Eighty percent of the studies we examined were conducted in healthy patients despite Thomson's comment, and those of at least one earlier reviewer, ${ }^{12}$ that these patients are unlikely to be harmed. Thomson stressed that overall outcome is important, especially if investigators then make recommendations. Only one in 10 investigators commented on long term outcome, but almost half made recommendations.

Thomson made no comparisons of the modifying drugs that had been tested up to that time. He had no need to, because his criticisms cast doubt on the validity of the whole field of study. Despite referring to previous studies of drugs to blunt the response, there were no comparisons with other active drugs in half of the studies we examined. It is almost as if the investigators were doing studies isolated from any background of knowledge other than the well established fact that there is a haemodynamic response. Even if investigators had considered Thomson's four points when designing their studies, choice of treatment is impossible without comparisons. Certainly, any new approach to preventing the haemodynamic response has to be tested first in patients not at risk, but enough is now known for comparative studies in patients at risk. Patients with cardiovascular disease may show not just exaggerated hypertensive responses; they may also be harmed by hypotension secondary to efforts to prevent hypertension.

Brooks studied why investigators make the citations they do ('citer motivations'), ${ }^{6}$ and three of his seven motivations could have prompted citation of Thomson: 'persuasiveness' (need to convince peers of correctness of methods and results - which is perhaps why almost no one cited Thomson's editorial since it is a sound argument for not doing many of these studies); 'currency' (prestige sought through referring to the latest work of their contemporaries); and 'reader alert' (providing background reading, alerting to new work and providing leads). Shadish and co-workers ${ }^{13}$ listed four main reasons given by authors for citing a particular reference. Three of the 11 most frequently cited papers could be considered to be in his class of 'classic references in the field'. Citations to studies using attenuating drugs come into two classes: 'concept markers' or 'supporting an assertion'.

It was often not clear to us why a particular citation to a study investigating a drug had been chosen from a group of studies of similar drugs. For example, in two papers published in 1994 comparing the effects of calcium channel antagonists with placebo, either four or five of the available 14 citations were made, and citation was inconsistent between the calcium channel antagonists studied by the investigators and studied in the cited work. The chosen citations were not always the first uses of these drugs. There was certainly the well known tendency ${ }^{14,15}$ towards self-citation and national bias. We did not find any evidence that investigators look at previous papers from other groups and pick up citations from them, though we did not test this statistically. The research groups used similar lists of references for all their papers; this was particularly obvious for the group whose citations remained similar throughout their 16 papers published in six journals over five years.

There may be genuine difficulties deciding, in advance, what research is truly original and worthwhile. Hindsight is an easy tool for dismissing a body of work. It is clear from our survey that researchers either failed to look for previous work on their research topic, or chose to ignore what they found. Thomson's points are well argued, and two-thirds of researchers made exactly the mistakes that he warns about. Even those researchers who drew conclusions from their studies that are in line with Thomson 
should have known that he had made them before they did their studies. The journals, through their referees, must share some of the responsibility and some of the blame. We are here criticizing anaesthetists for lacking research discipline, but that is only because our approach was enabled by a circumscribed research topic in our own specialty. We doubt that the problem is limited to the specialty of anaesthesia. When patients give their informed consent to take part in clinical studies, we owe it to them that the studies we do are properly researched and worthwhile.

\section{Conclusion}

Investigators of the haemodynamic response to intubation have either failed to review previous work adequately, or have chosen not to cite opinion critical of it. This almost certainly happens in other fields of study within anaesthesia, and throughout medicine. Part of the responsibility lies with journals and their expert assessors, but one partial solution is what Chalmers et al. suggested. Investigators, when they submit work for peer review, must provide evidence of "an exhaustive search of the published literature."4

\section{References}

1 Carpenter $L M$. Is the study worth doing? Lancet 1993; 342: 221-3.

2 Calne $D B$, Calne $R$. Citation of original research (Letter). Lancet 1992; 340: 244.

3 Altman DG. The scandal of poor medical research (Editorial). BMJ 1994; 308: 283-4.

4 Chalmers TC, Frank CS, Reitman D. Minimizing the three stages of publication bias. JAMA 1990; 263: 1392-5.

5 Thomson IR. The haemodynamic response to intubation: a perspective (Editorial). Can J Anaesth 1989; 36: 367-9.

6 Brooks TA. Private acts and public objects: an investigation of citer motivations. Journal of the American Society for Information Science 1985; 36: 223-9.

7 Dickersin $K$, Scherer $R$, Lefebvre $C$. Identifying relevant studies for systematic reviews. BMJ 1994; 309 : 1286-91.

8 Fox EJ, Sklar GS, Hill CH, Villanueva R, King BD. Complications related to the pressor response to endotracheal intubation. Anesthesiology 1977; 47: 524-5.

9 Tsementzis SA, Hitchcock ER. Outcome from "rescue clipping" of ruptured intracranial aneurysms during induction anaesthesia and endotracheal intubation. J Neurol Neurosurg Psychiatry 1985; 48: 160-3.

10 Prys-Roberts C, Meloche R. Management of anesthesia in patients with hypertension or ischemic heart disease. Int Anesthesiol Clin 1979; 18: 181-217.
11 Roy WL, Edelist G, Gilbert B. Myocardial ischemia during non-cardiac surgical procedures in patients with coronary-artery disease. Anesthesiology 1979; 51 : 393-7.

$12 \mathrm{Ng}$ WS. Pathophysiological effects of tracheal intubation. In: Latto IP, Rosen M (Eds.). Difficulties in Tracheal Intubation. Eastbourne, UK: Baillière Tindall, 1985: 12-35.

13 Shadish WR, Tolliver D, Gray M, Sen Gupta SK. Author judgements about works they cite: three studies from psychology journals. Social Studies of Science 1995; 25: 477-98.

14 MacRoberts $M H$, MacRoberts BR. Problems of citation analysis: a critical review. Journal of the American Society for Information Science 1989; 40: 342-9.

15 Campbell FM. National Bias: a comparison of citation practices by health professionals. Bull Med Libr Assoc $1990 ; 78$ : 376-82.

A list of the 81 papers surveyed is available from the authors. If not requesting via $\mathrm{E}$-mail, please enclose a stamped addressed envelope. 